\title{
Efficacy of budesonide/formoterol maintenance and reliever therapy compared with higher-dose budesonide as step-up from low-dose inhaled corticosteroid treatment
}

\author{
Christine R. Jenkins ${ }^{1 *}$, Göran Eriksson², Eric D. Bateman ${ }^{3}$, Helen K. Reddel ${ }^{4}$, Malcolm R. Sears ${ }^{5}$,
} Magnus Lindberg ${ }^{6}$ and Paul M. O'Byrne ${ }^{5}$

\begin{abstract}
Background: Asthma management may involve a step up in treatment when symptoms are not well controlled. We examined whether budesonide/formoterol maintenance and reliever therapy (MRT) is as effective as higher, fixed-dose budesonide plus as-needed terbutaline in patients requiring step-up from Step 2 treatment (low-dose inhaled corticosteroids), stratified by baseline reliever use.

Methods: A post-hoc analysis utilized data from three clinical trials of 6-12 months' duration. Patients aged $\geq 12$ years with symptomatic asthma uncontrolled despite Step 2 treatment were included. Severe exacerbation rate, lung function and reliever use were analysed, stratified by baseline reliever use $(<1,1-2$ and $>2$ occasions/day).

Results: Overall, 1239 patients were included. Reductions in severe exacerbation rate with budesonide/formoterol MRT versus fixed-dose budesonide were similar across baseline reliever use levels, and were statistically significant in patients using 1-2 (42\%, $p=0.01)$ and $>2(39 \%, p=0.02)$ reliever occasions/day, but not $<1$ reliever occasion/day $(35 \%, p=0.11)$. Both treatments significantly increased mean $\mathrm{FEV}_{1}$ from baseline; improvements were significantly greater for budesonide/formoterol MRT in all reliever use groups. Reductions in reliever use from baseline were significantly greater with budesonide/formoterol MRT versus fixed-dose budesonide in patients using 1-2 and $>2$ reliever occasions/day ( -0.33 and -0.74 occasions/day, respectively).
\end{abstract}

Conclusions: Treatment benefit with budesonide/formoterol MRT versus higher, fixed-dose budesonide plus short-acting $\beta_{2}$-agonist was found in Step 2 patients with relatively low reliever use, supporting the proposal that budesonide/ formoterol MRT may be useful when asthma is uncontrolled with low-dose inhaled corticosteroid.

Keywords: Asthma, Bronchodilators, Corticosteroids, Respiratory therapy, Therapy

\footnotetext{
* Correspondence: christine.jenkins@sydney.edu.au

'Department of Thoracic Medicine, Concord Hospital and The George

Institute for Global Health, PO Box M201Missenden Rd, Sydney, NSW 2050,

Australia

Full list of author information is available at the end of the article
} 


\section{Background}

Mild asthma comprises approximately $70 \%$ of asthma in the community [1], and accounts for a significant economic burden [2]. Despite this, the principal focus of most research has been in patients with more severe asthma. The long-term goals of asthma management are to achieve good control of symptoms and to minimise future risk to the patient, including exacerbations [3]. Whilst poor symptom control is a well-known predictor of risk of exacerbations [4], even patients with well controlled asthma symptoms may continue to experience exacerbations, and require interventions to reduce this risk.

The Global Initiative for Asthma (GINA) report recommends control-based asthma management, with pharmacological and non-pharmacological treatments adjusted in a continuous cycle based on assessment of symptom control and risk factors; a step up in treatment is recommended if asthma symptoms are not well controlled or if exacerbations continue despite good adherence and correct technique with the patient's existing inhaled treatment [3]. The recommended treatment at Step 2 is low-dose inhaled corticosteroid (ICS) as maintenance treatment plus as-needed short-acting $\beta_{2}$-agonist (SABA) as reliever medication [3]. It was established in the 1990s that, for those needing a step up in treatment, maintenance therapy with a low-dose ICS/longacting $\beta_{2}$-agonist (ICS/LABA) plus as-needed SABA as reliever was more effective than a two- or four-fold higher dose of ICS [5, 6]; hence, the preferred Step 3 options are either low-dose ICS/formoterol, such as budesonide/formoterol (BUD/FORM), as both maintenance and reliever therapy (MRT), or conventional maintenance treatment with low-dose ICS/LABA plus as-needed SABA as reliever. An alternative Step 3 option is a twoor even four-fold higher dose of ICS plus as-needed SABA as reliever [3]. The latter is equally recommended with maintenance low-dose ICS/LABA in the US guidelines (Expert Panel Report 3) [7], and is the recommended Step 3 treatment in the International Union Against Tuberculosis and Lung Disease guidelines [8].

We have previously shown in a post-hoc analysis of five studies that, in patients with sub-optimal asthma control despite GINA Step 2, 3 or 4 treatment, BUD/ FORM MRT is more effective in improving symptom control and reducing exacerbations than higher-dose ICS [9]. However, most patients in these studies had poor symptom control at entry, with mean reliever use of 1.7 to 2.4 occasions/day, which is well above the criterion of SABA use of $\geq 3$ occasions/week at which a step-up would normally be considered.

Thus, it is relevant to question whether BUD/FORM MRT is effective in patients with milder, less poorly controlled disease at study entry, i.e. those with less frequent reliever use while taking low-dose ICS $(\leq 400 \mu \mathrm{g} /$ day BUD equivalent). This post-hoc analysis evaluated the efficacy of BUD/FORM MRT in improving exacerbation rate, lung function and reliever use compared with reference treatment of a higher, fixed dose of BUD plus as-needed SABA in such patients, stratified by baseline reliever use.

\section{Methods}

\section{Study design}

This retrospective, post-hoc analysis included data from double-blind, randomized, parallel-group studies of 6 [10] and 12 [11, 12] months' duration. The detailed methodologies have been published elsewhere [10-12]. Briefly, the clinical studies investigated the efficacy of BUD/ FORM 160-320/9 $\mu \mathrm{g} /$ day MRT (Symbicort SMART ${ }^{\mathrm{m}}$; AstraZeneca, Lund, Sweden) compared with fixed-dose BUD $320-640 \mu \mathrm{g} /$ day as maintenance therapy and the SABA, terbutaline $0.4 \mathrm{mg}$, as needed. A fixed dose of BUD/ FORM 160/9 $\mu \mathrm{g}$ maintenance therapy plus terbutaline $0.4 \mathrm{mg}$ as-needed treatment arm was investigated as a comparator only in one [12] of three studies and was not included in the present analysis for this reason. All study drugs were administered using Turbuhaler (AstraZeneca, Lund, Sweden) dry powder inhaler as delivered doses. Patients were permitted to take a maximum of 10 asneeded occasions/day of BUD/FORM or terbutaline before contacting the investigator for reassessment. The studies were performed in accordance with the Declaration of Helsinki and Good Clinical Practice guidelines. Approval from regulatory agencies and ethics committees was obtained at all centres. All patients gave written informed consent.

\section{Patients}

Patients aged 12-80 [10, 11] and 4-80 [12] years and with a diagnosis of asthma were enrolled in the clinical studies. Inclusion criteria comprised: a forced expiratory volume in $1 \mathrm{~s}\left(\mathrm{FEV}_{1}\right)$ of $60-100 \%$ predicted in two studies $[10,12]$, and $\mathrm{FEV}_{1} 50-90 \%$ predicted in the third study [11]; baseline bronchodilator reversibility of $\geq 12 \%$; and, in two studies [11, 12], at least one exacerbation in the 12 months prior to enrolment. Patients were required to have a minimum of $7[10]$ and $12[11,12]$ as-needed occasions of terbutaline during the last 10 days of run-in for enrolment, but no more than 10 occasions on any day. All patients received ICS $(200-1600 \mu \mathrm{g} /$ day $)$ for $\geq 3$ months and at a constant dose for 30 days prior to study entry.

In the present post-hoc analysis, patients with asthma aged $\geq 12$ years who were receiving Step 2 treatment (low-dose ICS, $\leq 400 \mu \mathrm{g} /$ day BUD equivalent, and no long-acting $\beta_{2}$ agonist therapy) were included. Outcomes were analysed across a range of baseline reliever use 
levels: $<1,1-2$ and $>2$ occasions/day. These cut-points were chosen for clinical simplicity rather than based on statistical distribution.

\section{Efficacy evaluations}

A severe exacerbation was defined as hospitalization/ emergency department treatment due to asthma worsening or the need for oral steroid treatment of asthma (as judged by the investigator). $\mathrm{FEV}_{1}$ measurements were assessed by spirometry at enrolment and all clinic visits, and in accordance with the European Respiratory Society recommendations [13]. Use of reliever medication (terbutaline or BUD/FORM according to randomised allocation) was recorded by patients using diary cards.

\section{Statistical analysis}

Efficacy analysis was carried out for each study variable to determine whether BUD/FORM MRT was more efficacious than fixed-dose BUD by baseline reliever use $(<1,1-2$ and $>2$ occasions/day). Severe exacerbation rates were analysed using Poisson regression with treatment and study as factors, and presented as $\mathrm{p}$ values and 95\% confidence intervals (CI). On-treatment $\mathrm{FEV}_{1}$ [14] and reliever use were analysed as treatment average change from baseline using analysis of covariance (ANCOVA) with treatment, study and baseline as fixed factors; least-square mean [LSM] treatment differences and $95 \%$ CI were calculated. In addition, the proportion of patients on both treatments with baseline reliever use $\geq 1$ and $>2$ occasions/day who achieved a reduction in mean reliever use to thresholds of $<0.5$ and $<1$ occasion/ day was analysed using Fisher's exact test; patients with baseline reliever use $\geq 1$ occasions/day comprise those from both the 1-2 and $>2$ occasions/day baseline reliever use subgroups. $\mathrm{P}$ values $<0.05$ were considered statistically significant. Statistical analysis was performed using standard statistical software (SAS v9.2, SAS Institute Inc., NC, USA).

\section{Results}

\section{Patients}

In total, 1239 patients (BUD/FORM MRT = 626; fixeddose BUD = 613) were included in this post-hoc analysis. Baseline data for these patients are presented in Table 1. Baseline characteristics between randomization groups were comparable, including lung function, reliever use and ICS dose, but as expected baseline lung function was lower in the groups with highest baseline reliever use (Table 1).

\section{Severe exacerbations}

The percentage of patients with a severe exacerbation generally increased with increasing baseline reliever use for both treatments (Table 2). In all baseline reliever use groups, the percentage of patients with a severe exacerbation was lower with BUD/FORM MRT than fixeddose BUD (Table 2).

Severe exacerbation rates for patients treated with BUD/FORM MRT and fixed-dose BUD stratified by baseline reliever use levels are shown in Table 2 . In the group using reliever on $<1$ occasion/day at baseline, there was a $35 \%$ reduction in severe exacerbations for BUD/FORM MRT versus fixed-dose BUD (mean 0.09 vs 0.14 severe exacerbations per year, respectively; Table 2), but this effect did not reach statistical significance (rate ratio $=0.65$ [95\% CI: $0.38,1.11] ; p=0.11$; Fig. 1 ). In the baseline reliever use 1-2 occasions/day group, exacerbation rates for patients treated with BUD/FORM MRT and fixed-dose BUD were mean 0.09 and 0.16 exacerbations per year, respectively (Table 2), corresponding with a $42 \%$ reduction in severe exacerbations (rate ratio= 0.58 [95\% CI: 0.38, 0.88]; $p=0.01$; Fig. 1) for BUD/ FORM MRT compared with fixed-dose BUD. Among patients with reliever use $>2$ occasions/day at baseline, patients treated with BUD/FORM MRT had fewer severe exacerbations than those treated with fixed-dose BUD (mean 0.22 vs 0.37 exacerbations per year, Table 2), corresponding with a $39 \%$ lower reduction in severe exacerbations (rate ratio $=0.61$ [95\% CI: 0.40, 0.93]; $p=0.02$; Fig. 1).

FEV $_{1}$

Both BUD/FORM MRT and fixed-dose BUD significantly improved mean $\mathrm{FEV}_{1}$ from baseline in all three reliever use groups; for both treatments, improvements from baseline were greatest in patients with baseline reliever use $>2$ occasions/day (Table 2). For all reliever use groups, improvements from baseline in mean $\mathrm{FEV}_{1}$ were significantly greater for BUD/ FORM MRT compared with fixed-dose BUD (treatment differences: $<1$ occasion/day $=+0.11$ L [95\% CI: $0.04,0.17], \quad p=0.001 ; 1-2$ occasions/day $=+0.11 \mathrm{~L}$ [95\% CI: $0.06,0.16], p<0.0001 ;>2$ occasions/day $=$ +0.10 L [95\% CI: 0.02, 0.17], $p=0.01$; Fig. 2).

\section{Reliever use}

Both BUD/FORM MRT and fixed-dose BUD reduced reliever use from baseline in all three baseline reliever use groups (Table 2); reductions were greater with increasing baseline reliever use and were most prominent in patients using $>2$ occasions/day. In patients using $<1$ reliever occasion/day at baseline, reductions in reliever use for BUD/FORM MRT compared with fixed-dose BUD were not statistically significant; treatment difference $=-0.03$ occasions/day, $p=0.68$ (Table 2, Fig. 3) . Among patients using 1-2 and $>2$ reliever occasions/day at baseline, reductions in mean reliever use were significantly greater for BUD/FORM MRT than fixed-dose 
Table 1 Patients' baseline and demographic data, stratified by baseline reliever use $(<1,1-2$ and $>2$ occasions/day)

\begin{tabular}{|c|c|c|c|c|c|c|c|c|}
\hline & \multirow{3}{*}{$\begin{array}{l}\text { BUD/FORM MRT } \\
\text { (All patients) } \\
\text { ( } n=626)\end{array}$} & \multirow{3}{*}{$\begin{array}{l}\text { Fixed-dose BUD } \\
\text { (All patients) } \\
\text { ( } n=613)\end{array}$} & \multicolumn{6}{|c|}{ Baseline reliever use subgroup } \\
\hline & & & \multicolumn{2}{|c|}{$<1$ occasion/day } & \multicolumn{2}{|c|}{ 1-2 occasions/day } & \multicolumn{2}{|c|}{$>2$ occasions/day } \\
\hline & & & $\begin{array}{l}\text { BUD/FORM } \\
\text { MRT }(n=168)\end{array}$ & $\begin{array}{l}\text { Fixed-dose } \\
\text { BUD }(n=155)\end{array}$ & $\begin{array}{l}\text { BUD/FORM } \\
\text { MRT }(n=257)\end{array}$ & $\begin{array}{l}\text { Fixed-dose } \\
\text { BUD }(n=253)\end{array}$ & $\begin{array}{l}\text { BUD/FORM } \\
\text { MRT }(n=201)\end{array}$ & $\begin{array}{l}\text { Fixed-dose } \\
\text { BUD }(n=205)\end{array}$ \\
\hline Male, n (\%) & $254(40.6)$ & $227(37.0)$ & $71(42.3)$ & $58(37.4)$ & $104(40.5)$ & $100(39.5)$ & 79 (39.3) & $69(33.7)$ \\
\hline Age, year & $37.0(15.9)$ & $38.3(16.5)$ & $35.6(15.7)$ & $37.5(16.0)$ & $36.0(16.2)$ & $37.7(17.0)$ & $39.4(15.5)$ & $39.6(16.1)$ \\
\hline $\begin{array}{l}\text { Duration of } \\
\text { asthma, years }^{\text {a }}\end{array}$ & 10 & 9 & 7 & 8 & 10 & 10 & 11 & 10 \\
\hline $\begin{array}{l}\text { Dose of inhaled } \\
\text { corticosteroid, } \\
\mu \mathrm{g} / \text { day BUD eqv }\end{array}$ & $357.8(70.2)$ & $356.1(70.8)$ & $339.9(84.6)$ & $325.4(88.1)$ & $359.9(71.0)$ & $367.2(63.2)$ & $370.1(51.0)$ & $365.6(57.4)$ \\
\hline $\begin{array}{l}\text { Pre-BD FEV } 1 \% \\
\text { predicted }\end{array}$ & $73.6(10.9)$ & $73.0(10.7)$ & $74.0(11.2)$ & $74.0(11.1)$ & $74.8(10.6)$ & $73.4(10.6)$ & 71.7 (10.6) & $71.7(10.5)$ \\
\hline $\begin{array}{l}\text { Post-BD FEV }{ }_{1} \% \\
\text { predicted }\end{array}$ & $88.5(12.6)$ & $88.0(12.9)$ & $89.4(12.9)$ & $89.0(13.6)$ & $89.5(11.7)$ & $88.5(12.4)$ & $86.5(13.2)$ & $86.8(12.8)$ \\
\hline $\begin{array}{l}\text { Baseline pre-BD } \\
\mathrm{FEV}_{1}, \mathrm{~L}\end{array}$ & $2.41(0.7)$ & $2.35(0.7)$ & $2.51(0.7)$ & $2.47(0.7)$ & $2.46(0.7)$ & $2.41(0.8)$ & $2.26(0.7)$ & $2.19(0.7)$ \\
\hline $\begin{array}{l}\text { Baseline } \mathrm{FEV}_{1} \\
\text { reversibility, \% }\end{array}$ & $14.9(7.5)$ & $15.0(7.8)$ & $15.4(7.0)$ & $15.0(8.0)$ & $14.7(7.6)$ & $15.0(7.9)$ & $14.9(7.9)$ & $15.1(7.6)$ \\
\hline $\begin{array}{l}\text { Current smoker/ } \\
\text { ex-smoker, n (\%) }\end{array}$ & 117 (18.7) & 114 (18.6) & 26 (15.5) & $24(15.5)$ & $52(20.2)$ & 47 (18.6) & 39 (19.4) & $43(21.0)$ \\
\hline
\end{tabular}

Data are given as mean (SD), unless otherwise stated

Patients treated with BUD/FORM MRT comprised 254 patients from the STEAM study, [10] 171 patients from the STEP study, [11] and 201 patients from the STAY study [12]

Patients treated with fixed-dose BUD comprised 255 patients from the STEAM study, [10] 161 patients from the STEP study, [11] and 197 patients from the STAY study [12]

${ }^{a}$ Median

$B D$ bronchodilator, $B U D$ budesonide, eqv equivalent, $F E V_{1}$ forced expiratory volume in $1 \mathrm{~s}, F O R M$ formoterol, MRT maintenance and reliever therapy, SD standard deviation

Table 2 Clinical outcomes for patients treated with BUD/FORM MRT or fixed-dose BUD, stratified by baseline reliever use $(<1,1-2$ and $>2$ occasions/day)

\begin{tabular}{|c|c|c|c|c|c|c|c|}
\hline \multirow{3}{*}{$\begin{array}{l}\text { BUD/FORM MRT } \\
\text { (All patients) } \\
(n=626)\end{array}$} & \multirow{3}{*}{$\begin{array}{l}\text { Fixed-dose BUD } \\
\text { (All patients) } \\
(n=613)\end{array}$} & \multicolumn{6}{|c|}{ Baseline reliever use subgroup } \\
\hline & & \multicolumn{2}{|c|}{$<1$ occasion/day } & \multicolumn{2}{|c|}{ 1-2 occasions/day } & \multicolumn{2}{|c|}{$>2$ occasions/day } \\
\hline & & $\begin{array}{l}\text { BUD/FORM } \\
\text { MRT }(n=168)\end{array}$ & $\begin{array}{l}\text { Fixed-dose } \\
\text { BUD }(n=155)\end{array}$ & $\begin{array}{l}\text { BUD/FORM } \\
\text { MRT }(n=257)\end{array}$ & $\begin{array}{l}\text { Fixed-dose } \\
\text { BUD }(n=253)\end{array}$ & $\begin{array}{l}\text { BUD/FORM } \\
\text { MRT }(n=201)\end{array}$ & $\begin{array}{l}\text { Fixed-dose } \\
\text { BUD }(n=205)\end{array}$ \\
\hline
\end{tabular}

\begin{tabular}{|c|c|c|c|c|c|c|c|c|}
\hline \multicolumn{9}{|l|}{ Severe exacerbations } \\
\hline $\begin{array}{l}\text { Patients with severe } \\
\text { exacerbation, } \mathrm{n}(\%)\end{array}$ & $38(6.1)$ & $72(11.7)$ & $8(4.8)$ & $11(7.1)$ & $11(4.3)$ & $24(9.5)$ & $19(9.5)$ & $37(18.0)$ \\
\hline $\begin{array}{l}\text { Rate, exacerbations } \\
\text { per year }\end{array}$ & 0.14 & 0.23 & 0.09 & 0.14 & 0.09 & 0.16 & 0.22 & 0.37 \\
\hline \multicolumn{9}{|l|}{$\mathrm{FEV}_{1}$} \\
\hline $\mathrm{FEV}_{1}, \mathrm{~L}$ & $2.62(0.8)$ & $2.46(0.7)$ & $2.69(0.7)$ & $2.55(0.7)$ & $2.66(0.8)$ & $2.50(0.8)$ & $2.51(0.8)$ & $2.34(0.7)$ \\
\hline $\begin{array}{l}\text { Change from baseline } \\
\text { in } \mathrm{FEV}_{1}, \mathrm{~L}\end{array}$ & $0.21(0.3)$ & $0.11(0.3)$ & $0.18(0.3)$ & $0.08(0.3)$ & $0.20(0.3)$ & $0.10(0.3)$ & $0.25(0.4)$ & $0.16(0.4)$ \\
\hline \multicolumn{9}{|l|}{ Reliever use } \\
\hline $\begin{array}{l}\text { Treatment period reliever } \\
\text { use, occasions/day }\end{array}$ & $0.84(1.2)$ & $1.27(1.5)$ & $0.43(0.7)$ & $0.50(0.8)$ & $0.60(0.7)$ & $0.93(1.0)$ & $1.50(1.7)$ & $2.28(1.7)$ \\
\hline $\begin{array}{l}\text { Change from baseline in } \\
\text { reliever use, occasions/day }\end{array}$ & $-1.00(1.3)$ & $-0.65(1.3)$ & $-0.15(0.7)$ & $-0.15(0.8)$ & $-0.89(0.8)$ & $-0.56(1.0)$ & $-1.84(1.6)$ & $-1.14(1.7)$ \\
\hline
\end{tabular}




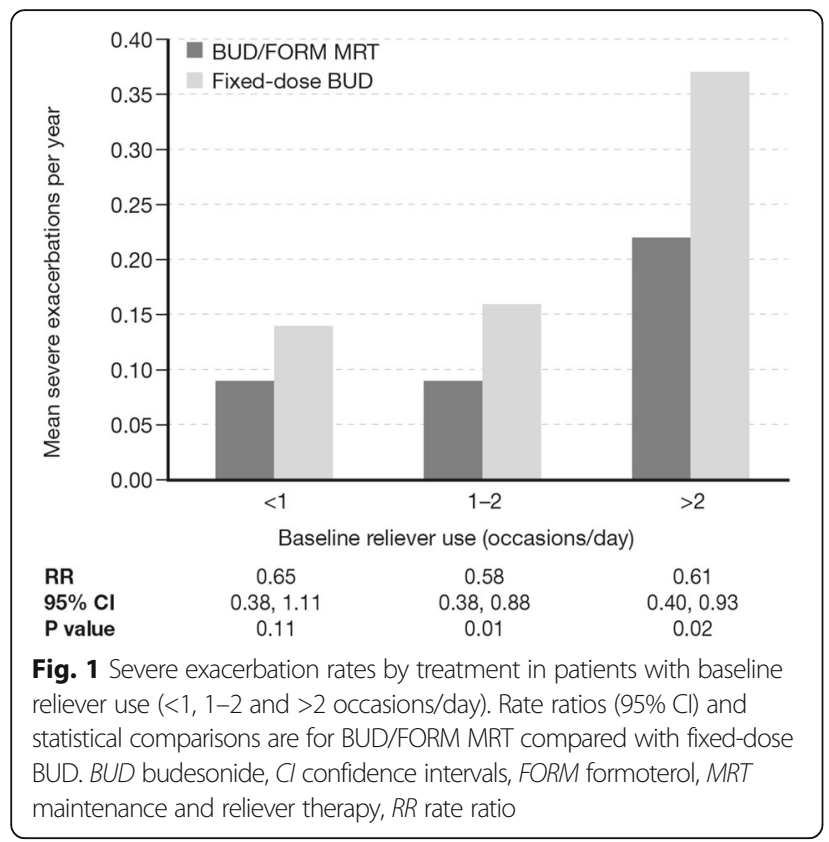

BUD; $1-2$ occasions/day: treatment difference $=-0.33$ occasions/day, $p<0.0001$; $>2$ occasions/day: treatment difference $=-0.74$ occasions $/$ day, $p<0.0001$ (Table 2, Fig. 3).

For patients with baseline reliever use $\geq 1$ and $>2$ occasions/day, the proportion of patients who achieved a reduction in mean reliever use to thresholds of $<0.5$ and $<1$ occasion/day was significantly greater with

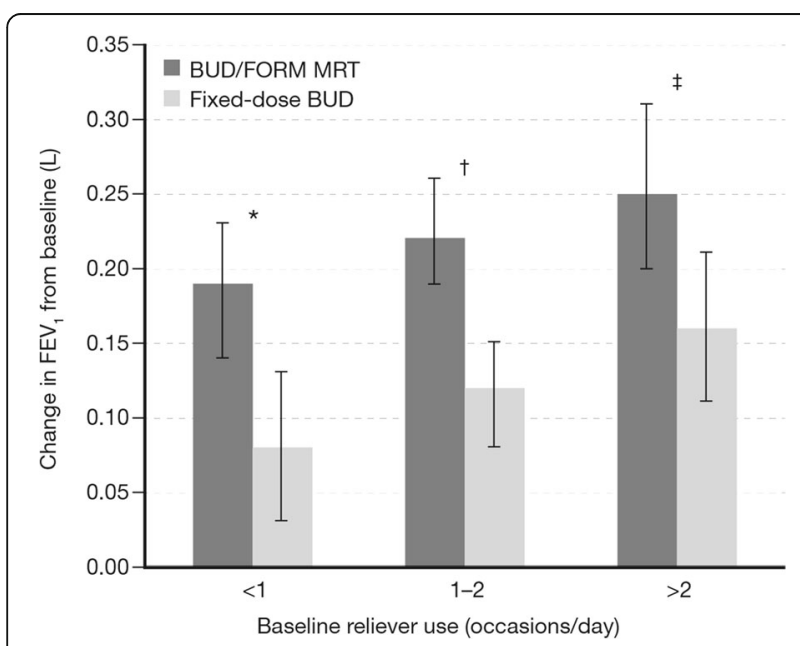

Fig. 2 Least square mean improvements in mean $\mathrm{FEV}_{1}$ from baseline in patients treated with BUD/FORM MRT or fixed-dose BUD, stratified by baseline reliever use $(<1,1-2$ and $>2$ occasions/day). The error bars represent $95 \% \mathrm{Cl}$. Statistical comparisons are for BUD/FORM MRT compared with fixed-dose BUD. BUD budesonide, Cl confidence intervals, FORM formoterol, FEV 1 forced expiratory volume in $1 \mathrm{~s}$, MRT maintenance and reliever therapy. ${ }^{*}+0.11 \mathrm{~L}(95 \% \mathrm{Cl}: 0.04,0.17), p=0.001$; $\dagger+0.11$ L (95\% Cl: $0.06,0.16), p<0.0001 ; \neq+0.10$ L (95\% Cl: 0.02, 0.17), $p=0.01$

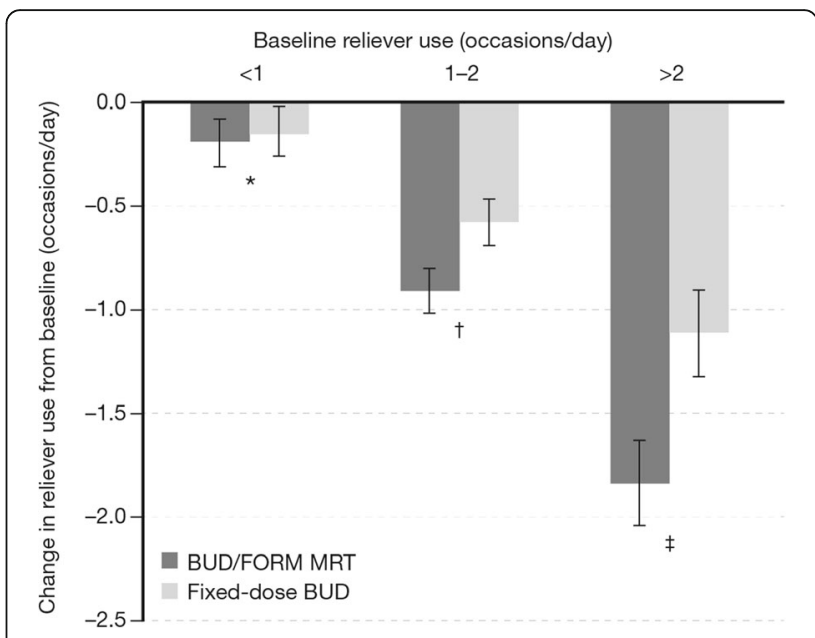

Fig. 3 Least square mean improvements in on-treatment reliever use from baseline in patients treated with BUD/FORM MRT or fixed-dose BUD, stratified by baseline reliever use $(<1,1-2$ and $>2$ occasions/day). The error bars represent $95 \% \mathrm{Cl}$. Statistical comparisons are for BUD/ FORM MRT compared with fixed-dose BUD. BUD budesonide, CI confidence intervals, FORM formoterol, MRT maintenance and reliever therapy. ${ }^{*}-0.03$ occasions/day (95\% Cl: $\left.-0.20,0.13\right), p=0.68$; $\dagger$ -0.33 occasions/day (95\% Cl: $-0.48,-0.18), p<0.0001 ; \neq-0.74$ occasions/ day $(95 \% \mathrm{Cl}:-1.03,-0.45), p<0.0001$

BUD/FORM MRT than fixed-dose BUD (all $p<$ 0.0001, Additional file 1: Table S1).

\section{Discussion}

The efficacy of BUD/FORM MRT for reducing exacerbations in at-risk patients with uncontrolled asthma across a range of baseline treatment steps is well established [9]. The present post-hoc analysis, based on patients using Step 2 treatment (low-dose ICS, $\leq 400 \mu \mathrm{g} /$ day BUD equivalent) at entry into three double-blind, randomized, parallel-group studies [10-12], and stratifying by baseline reliever use $(<1,1-2$ and $>2$ occasions/day), suggests that the benefit from MRT is seen even in patients with milder asthma and impaired asthma control, most of whom had a history of at least one exacerbation in the previous year. The magnitude of difference in severe exacerbations for MRT compared with higher-dose ICS was similar regardless of baseline reliever use, reducing the proportion of patients having a severe exacerbation by $35-42 \%$; however, statistical significance was not reached in the lowest stratum. Furthermore, this reduction in exacerbation risk with BUD/FORM MRT was achieved with a maintenance dose of ICS approximately two-[10, 11] to four-[12] fold lower than with fixed-dose BUD. This finding supports the value of MRT treatment in this milder category of asthma in terms of reducing exacerbation risk. Importantly, exacerbation reduction may still be important in this group of patients with low exacerbation rates since a significant proportion of 
asthma deaths occur in patients with so-called mild asthma [15-17].

This study also considers a problem common in clinical practice, that is, the situation in which patients use higher than recommended levels of reliever use before they or their physicians step up treatment [18]. The recommended approach in patients with mild asthma who remain uncontrolled and require reliever medication $\geq 3$ occasions/week [3] despite maintenance treatment with low-dose ICS $(<400 \mu \mathrm{g} /$ day BUD equivalent $)$ and asneeded SABA as reliever, is to check adherence and inhaler technique, and then to step up treatment to lowdose ICS/formoterol (budesonide or beclomethasone) MRT or low-dose maintenance ICS/LABA plus asneeded SABA [3]. A third option is medium-dose ICS plus as-needed SABA as reliever. Frequent reliever use is a marker for sub-optimal asthma control and is associated with an increased risk of an exacerbation [4]. The latter has been confirmed in many studies, and a recent comparison of BUD/FORM MRT with conventional maintenance BUD/FORM and as-needed SABA showed that baseline reliever use was a significant predictor of severe exacerbations within the following 12 months [19].

Improvements in measures of daily asthma control (lung function, reliever use) were also seen for BUD/ FORM MRT compared with fixed-dose BUD. Given that the comparator was ICS alone, it is not surprising that improvements in on-treatment $\mathrm{FEV}_{1}$ [14] from baseline were significantly greater for BUD/FORM MRT than fixed-dose BUD (treatment differences 0.10-0.11 L). However, although statistically significant, improvements in $\mathrm{FEV}_{1}$ of $0.10-0.11 \mathrm{~L}$ are relatively small despite these patients having mean $15 \% \mathrm{FEV}_{1}$ reversibility and low prebronchodilator $\mathrm{FEV}_{1}$ at baseline. That the magnitude of reduction in reliever use with BUD/FORM MRT was smallest in patients with lower baseline reliever use suggests that these patients may have milder underlying asthma or may disregard some symptoms, or that reliever use at such low levels may be a relatively insensitive marker of treatment effect. Despite this, our exacerbation data suggest that there is still potential for clinical benefit by reducing their risk of adverse outcomes. Further to the mean changes in reliever use, BUD/FORM MRT significantly increased the proportion of patients with baseline usage $\geq 1$ and $>2$ occasions/day whose reliever use fell below 0.5 occasions/day (3.5 occasions/week), usage above which a step-up in treatment would normally be considered.

One mechanism by which BUD/FORM MRT may reduce exacerbations even in patients with infrequent reliever use is by improving adherence with ICScontaining medication. Poor adherence is associated with significant asthma-related morbidity but, despite this, patients with milder asthma may not take daily maintenance treatment on symptom-free days [20,21], which supports the rationale for the use of MRT in patients with reliever use of $<1$ occasion/day. The use of a single combination inhaler for ICS/LABA MRT simplifies asthma management and ensures that reliever treatment provides both immediate symptom relief and a rapid anti-inflammatory effect, preventing symptoms from developing into an exacerbation. There is also an established scientific rationale for giving an ICS and a LABA together as they have complementary actions on the pathophysiology of asthma and may act synergistically at a molecular level [22, 23].

We acknowledge that the post-hoc design of this analysis is a limitation and future prospective, welldesigned trials are required to confirm these findings in patients with milder asthma and lower baseline reliever use. The use of ICS/LABA as-needed in mild asthma is currently being evaluated in the ongoing SYGMA studies [24]. In the present analysis, the selection only of patients on Step 2 treatment at entry, and sub-division by baseline as-needed reliever use, reduced the power of the analyses, with only around 150-250 patients qualifying in each sub-group. Additionally, all patients satisfied the regulatory requirement for significant bronchodilator reversibility at entry, and the studies had minimum reliever use requirements of $7[10]$ and $12[11,12]$ occasions in the last 10 days of run-in, so the results cannot and should not be extrapolated to patients with well controlled asthma (e.g., with reliever use $<3$ occasions/ week). Finally, patients in two of the studies were required to have had at least one exacerbation in the previous 12 months and may thus represent a group of patients at higher risk than others at this step of treatment.

\section{Conclusions}

In conclusion, BUD/FORM MRT and a higher, fixed dose of BUD plus SABA improved lung function, and reduced reliever use and exacerbation rate, in patients whose asthma was uncontrolled on Step 2 treatment at study entry. Treatment benefit for exacerbations with BUD/FORM MRT compared with a higher, fixed-dose BUD plus SABA was found in these patients across all levels of baseline reliever use, and was statistically significant in those with a baseline reliever use of $1-2$ and $>2$ occasions/day. These results support the beneficial effects of BUD/FORM MRT in patients whose asthma is not well-controlled with low-dose ICS, even when their background use of reliever is relatively low. 


\section{Additional file}

Additional file 1: Table S1. Proportion of patients with baseline reliever use $\geq 1$ and $>2$ occasions/day who achieved mean reliever use thresholds of $<1$ and $<0.5$ occasion/day following treatment with BUD/ FORM MRT or fixed-dose BUD. (DOCX $14 \mathrm{~kb}$ )

\section{Abbreviations}

BD: Bronchodilator; BUD/FORM: Budesonide/formoterol; Cl: Confidence interval; FEV $\mathrm{F}_{1}$ : Forced expiratory volume in 1 second; GINA: Global Initiative for Asthma; ICS: Inhaled corticosteroids; LABA: Long-acting $\beta_{2}$-agonist; MRT: Maintenance reliever therapy; RR: Rate ratio; SABA: Short-acting $\beta_{2}$-agonist; SD: Standard deviation

\section{Acknowledgements}

Shaun Foley, inScience Communications, Springer Healthcare, provided medical writing assistance, funded by AstraZeneca.

\section{Funding}

AstraZeneca funded this post-hoc analysis. The authors generated the hypotheses of this post-hoc analysis, Magnus Lindberg (of AstraZeneca) performed the analyses on the pooled data from the three AstraZenecasponsored phase III studies, and distributed the data outputs to the authors, who were responsible for the interpretation of the data.

\section{Availability of data and materials}

The data sets supporting the conclusions of this article have previously been published as the results of 3 clinical trials that pre-dated the clinical trials.gov database.

Rabe KF, et al. Chest. 2006:129(2):246-56. doi:10.1378/chest.129.2.246.

Scicchitano R, et al. Current Medical Research and Opinion. 2004;20(9):1403-18. doi:10.1185/030079904X2051

O'Byrne PM, et al. American Journal of Respiratory and Critical Care Medicine. 2005;171(2):129-36. doi:10.1164/rccm.200407-884OC.

\section{Authors' contributions}

CJ, GE, EB, HR, MS, ML and PO contributed to data interpretation, and conceiving, writing and revising the manuscript. ML was responsible for statistical analyses. CJ, the corresponding author, had full access to all the data in the study and had final responsibility for the decision to submit for publication. All authors read and approved the final manuscript.

\section{Competing interests}

C. Jenkins has received consultancy fees, travel and expense support from AstraZeneca for participation in a working group that performed analyses of databases that led to this paper; has received consultancy fees for advisory board and/or steering committee membership from AstraZeneca,

GlaxoSmithKline, Boehringer Ingelheim, Novartis and Mundipharma; has received payment for delivering lectures from GlaxoSmithKline, Boehringer Ingelheim, AstraZeneca, Novartis and Mundipharma, and payment for the development of educational presentations from GlaxoSmithKline, Boehringer Ingelheim, AstraZeneca, Novartis, Mundipharma; and has also been paid an hourly rate for face-to-face individual consultations and for offering advice on regulatory issues for airways disease medications from GlaxoSmithKline, Boehringer Ingelheim, AstraZeneca and Novartis.

E. D. Bateman has received consulting fees from AstraZeneca for participation in a working group that performed analyses of databases that led to this paper; has received compensation for board membership from Almirall, AstraZeneca, Boehringer Ingelheim, GlaxoSmithKline, Merck, Novartis and Takeda; has received consultancy fees from ALK-Abelló, Almirall and Cephalon; has received or has grants pending from Actelion, Aeras, Almirall, AstraZeneca, Boehringer Ingelheim, GlaxoSmithKline, Roche/Genentech, Merck, Novartis, Takeda, TEVA and Cephalon; and has received payment for delivering lectures from AstraZeneca, Boehringer Ingelheim, Chiesi, GlaxoSmithKline, Novartis and Takeda, as well as from Novartis for the development of education presentations.

G. Eriksson was previously employed by AstraZeneca, from which he also received stock/stock options, and has thereafter received consultancy fees from ALK, Almirall, Novartis and Medicon Valley Inhalation Consortium. H. K. Reddel has received consultancy fees from AstraZeneca for face-to-face meetings at which this manuscript and other studies were discussed; has received compensation for board membership from AstraZeneca, GlaxoSmithKline, Merck and Novartis; has received consultancy fees from AstraZeneca and Novartis; has received grants from GlaxoSmithKline and AstraZeneca; and has received payment from AstraZeneca, Boehringer Ingelheim, GlaxoSmithKline, Novartis, Mundipharma and Teva for delivering independent educational presentations.

M. R. Sears has consultant arrangements with AstraZeneca and Novartis, has received payment for lectures from AstraZeneca and Merck, and holds an AstraZeneca endowed chair in Respiratory Epidemiology.

M. Lindberg is an employee of AstraZeneca and owns stock/options in the company.

P. M. O'Byrne has received compensation for board membership from the Joint Oversight Board for a LABA safety study, and has received consultancy fees from AstraZeneca, GlaxoSmithKline, Merck, Boehringer and Novartis, and has received or has grants pending from AstraZeneca, Amgen, Genentech, Axikin, Novartis and Sanofi.

\section{Consent for publication}

Not applicable.

\section{Ethics approval and consent to participate}

The studies were performed in accordance with the Declaration of Helsinki and Good Clinical Practice guidelines. Approval from regulatory agencies and ethics committees was obtained at all centres. All patients gave written informed consent. As this analysis was retrospective, no ethics approval was obtained or needed for this.

\section{Publisher's Note}

Springer Nature remains neutral with regard to jurisdictional claims in published maps and institutional affiliations.

\section{Author details}

${ }^{1}$ Department of Thoracic Medicine, Concord Hospital and The George Institute for Global Health, PO Box M201Missenden Rd, Sydney, NSW 2050, Australia. ${ }^{2}$ Department of Respiratory Medicine and Allergology, University Hospital, Lund, Sweden. ${ }^{3}$ Division of Pulmonology, Department of Medicine, University of Cape Town, Cape Town, South Africa. ${ }^{4}$ Clinical Management Group, Woolcock Institute of Medical Research, University of Sydney, Sydney, Australia. ${ }^{5}$ Michael G DeGroote School of Medicine, Faculty of Health Sciences, McMaster University, Hamilton, Canada. ${ }^{6}$ Biometrics and Information Sciences (B\&l), AstraZeneca R\&D, Mölndal, Sweden.

Received: 8 September 2016 Accepted: 28 March 2017

Published online: 20 April 2017

\section{References}

1. O'Byrne PM, Parameswaran K. Pharmacological management of mild or moderate persistent asthma. Lancet. 2006;368:794-803.

2. Sadatsafavi M, Lynd L, Marra C, Carleton B, Tan WC, Sullivan S, Fitzgerald JM. Direct health care costs associated with asthma in British Columbia. Can Respir J. 2010;17:74-80.

3. GINA Global strategy for asthma management and prevention. Updated 2015.

4. Bateman ED, Reddel HK, Eriksson G, Peterson S, Ostlund O, Sears MR, Jenkins C, Humbert M, Buhl R, Harrison TW, Quirce S, O'Byrne PM. Overall asthma control: the relationship between current control and future risk. J Allergy Clin Immunol. 2010;125:600-8. e6.

5. Greening AP, Ind PW, Northfield M, Shaw G. Added salmeterol versus higherdose corticosteroid in asthma patients with symptoms on existing inhaled corticosteroid. Lancet. 1994;344:219-24.

6. Woolcock A, Lundback B, Ringdal N, Jacques LA. Comparison of addition of salmeterol to inhaled steroids with doubling of the dose of inhaled steroids. Am J Respir Crit Care Med. 1996;153:1481-8.

7. National Asthma Education and Prevention Program. Expert panel report 3 (EPR-3): guidelines for the diagnosis and management of asthma - summary report. J Allergy Clin Immunol. 2007;120:S94-S138.

8. Ait-Khaled N, Enarson D, Chen-Yuan C, Marks G and Bissell K. Management of Asthma: A Guide to the Essentials of Good Clinical Practice. Third edition. International Union Against Tuberculosis and Lung Disease); 2008. http:// www.theunion.org/what-we-do/publications/english/pub_asthma-guide eng.pdf. 
9. Bateman ED, Harrison TW, Quirce S, Reddel HK, Buhl R, Humbert M, Jenkins CR, Peterson S, Ostlund O, O'Byrne PM, Sears MR, Eriksson GS. Overall asthma control achieved with budesonide/formoterol maintenance and reliever therapy for patients on different treatment steps. Respir Res. 2011;12:38.

10. Rabe KF, Pizzichini E, Stallberg B, Romero S, Balanzat AM, Atienza T, Lier PA, Jorup C. Budesonide/formoterol in a single inhaler for maintenance and relief in mild-to-moderate asthma: a randomized, double-blind trial. Chest. 2006;129:246-56.

11. Scicchitano R, Aalbers R, Ukena D, Manjra A, Fouquert L, Centanni S, Boulet $L P$, Naya IP, Hultquist $C$. Efficacy and safety of budesonide/formoterol single inhaler therapy versus a higher dose of budesonide in moderate to severe asthma. Curr Med Res Opin. 2004;20:1403-18.

12. O'Byrne PM, Bisgaard H, Godard PP, Pistolesi M, Palmqvist M, Zhu Y, Ekstrom T, Bateman ED. Budesonide/formoterol combination therapy as both maintenance and reliever medication in asthma. Am J Respir Crit Care Med. 2005;171:129-36.

13. Quanjer PH, Tammeling GJ, Cotes JE, Pedersen OF, Peslin R, Yernault JC Lung volumes and forced ventilatory flows. Report working party standardization of lung function tests, European community for steel and coal. Official statement of the European Respiratory Society. Eur Respir J Suppl. 1993;16:5-40.

14. Reddel HK, Taylor DR, Bateman ED, Boulet LP, Boushey HA, Busse WW, Casale TB, Chanez P, Enright PL, Gibson PG, de Jongste JC, Kerstjens HA, Lazarus SC, Levy ML, O'Byrne PM, Partridge MR, Pavord ID, Sears MR, Sterk PJ, Stoloff SW, Sullivan SD, Szefler SJ, Thomas MD, Wenzel SE. An official American Thoracic Society/European Respiratory Society statement: asthma control and exacerbations: standardizing endpoints for clinical asthma trials and clinical practice. Am J Respir Crit Care Med. 2009;180:59-99.

15. Robertson CF, Rubinfeld AR, Bowes G. Pediatric asthma deaths in Victoria: the mild are at risk. Pediatr Pulmonol. 1992;13:95-100.

16. Royal College of Physicians 2014 Why asthma still kills. National Review of Asthma Deaths (NRAD). Report May 2014. (London

17. Abramson M J, Bailey M J, Couper F J, Driver J S, Drummer O H, Forbes A B, McNeil J J, Haydn Walters E and Victorian Asthma Mortality Study Group. Are asthma medications and management related to deaths from asthma? Am J Respir Crit Care Med. 2001:163:12-8.

18. Rabe KF, Adachi M, Lai CK, Soriano JB, Vermeire PA, Weiss KB, Weiss ST. Worldwide severity and control of asthma in children and adults: the global asthma insights and reality surveys. J Allergy Clin Immunol. 2004;114:40-7.

19. Bateman ED, Buhl R, O'Byrne PM, Humbert M, Reddel HK, Sears MR, Jenkins C, Harrison TW, Quirce S, Peterson S, Eriksson G. Development and validation of a novel risk score for asthma exacerbations: the risk score for exacerbations. J Allergy Clin Immunol. 2015;135:1457-64. e4.

20. Williams LK, Peterson EL, Wells K, Ahmedani BK, Kumar R, Burchard EG, Chowdhry VK, Favro D, Lanfear DE, Pladevall M. Quantifying the proportion of severe asthma exacerbations attributable to inhaled corticosteroid nonadherence. J Allergy Clin Immunol. 2011;128:1185-91. e2.

21. Patel M, Pilcher J, Pritchard A, Perrin K, Travers J, Shaw D, Holt S, Harwood M, Black P, Weatherall M, Beasley R. Efficacy and safety of maintenance and reliever combination budesonide-formoterol inhaler in patients with asthma at risk of severe exacerbations: a randomised controlled trial. Lancet Respir Med. 2013;1:32-42.

22. Barnes PJ. Scientific rationale for combination inhalers with a long-acting b2-agonists and corticosteroids. Eur Respir J. 2002;19:182-91.

23. Giembycz MA, Kaur M, Leigh R, Newton R. A holy grail of asthma management: toward understanding how long-acting $\beta 2$-adrenoceptor agonists enhance the clinical efficacy of inhaled corticosteroids. Br J Pharmacol. 2008;153:1094-104.

24. O'Byrne PM, FitzGerald JM, Zhong N, Bateman E, Barnes PJ, Keen C, Almqvist A, Pemberton K, Jorup C, Ivanov S, Reddel HK. The SYGMA programme of phase 3 trials to evaluate the efficacy and safety of budesonide/formoterol given 'as needed' in mild asthma: study protocols for two randomised controlled trials. Trials. 2017;18:12

\section{Submit your next manuscript to BioMed Central and we will help you at every step:}

- We accept pre-submission inquiries

- Our selector tool helps you to find the most relevant journal

- We provide round the clock customer support

- Convenient online submission

- Thorough peer review

- Inclusion in PubMed and all major indexing services

- Maximum visibility for your research

Submit your manuscript at www.biomedcentral.com/submit 